\title{
Dosimeter Film Based on Ethyl Violet-Bromophenol Blue Dyed Poly(Vinyl Alcohol)
}

\author{
Seif Ebraheem, Moushera El-Kelany \\ Radiation Protection and Dosimetry Department, National Center for Radiation, Research and Technology, \\ AEA, Madinat Nasr, Cairo, Egypt \\ Email: dr.moosh@hotmail.com
}

Received November 1, 2012; revised December 2, 2012; accepted December 14, 2012

\begin{abstract}
Dyed poly(vinyl alcohol) (PVA) films, prepared by a simple technique of casting aqueous solutions of PVA containing a mixture of Ethyl violet and bromophenol blue (EV-BPB) on a horizontal glass plate, are useful as routine high-dose dosimeter in the $1-30 \mathrm{kGy}$ range. The color of films changes from violet to yellow when exposed to gamma radiation. The response of this dosimeter depends up on the concentration of chloral hydrate $(\mathrm{CH})$ in the polymer material. The radiation chemical yield (G-value) of PVA dyed film was calculated and found to increase by increasing concentration of chloral hydrate. Post-irradiation storage on the response of the films are discussed. The overall combined uncertainty (at $2 \sigma$ ) associated with measurement of response $\left(\Delta A \mathrm{~mm}^{-1}\right)$ at $600 \mathrm{~nm}$ for dose range $1-15 \mathrm{kGy}$ is $5.6 \%$.
\end{abstract}

Keywords: Ethyl-Violet and Bromo-Phenol Blue; Poly(Vinyl Alcohol); Gamma Ray Dosimeter

\section{Introduction}

Treatment of food by radiation has rendered routine dosimeters and labels in the $1-30 \mathrm{kGy}$ range necessary. There are few solid-state dosimeters known to be applicable in this dose range, e.g. amber and Gammachrome perpex [1,2] and analnine dosimeters [3]. Radiation-sensitive indicators may be used to show that products have been exposed to radiation source. A new label dosimetry system based on the idea of mixing more than one dye having different sensitivities to radiation has been developed [4]. Radiation sensitive materials consisting of a chlorine-containing polymer and an acid-sensitive dye are known $[5,6]$. The chlorine-containing polymer is dehydro-chlorinated when the material is irradiated there by reducing $\mathrm{pH}$ and causing the acid-sensitive dye to change color. A similar color can be produced if a halogen-containing substance is present in the dye-containing matrix [7]. Many other films containing a radiation sensitive $\mathrm{pH}$ indicator dye with chloral hydrate have been prepared to be used $\gamma$-radiation monitoring dosimeters and indicators [8]. Radiation bleachable organic dyes were widely investigated [9], and for monitoring the absorbed dose delivered by electron beams and gamma rays [10]. A radiation dosimeter from acid indicators by coating a high molecular weight polymer support (e.g. polyester film) with a composition containing a halogen-containing polymer (e.g. PVC) developed [11], a pigment which changes color with the changes of $\mathrm{pH}$ and basic material (e.g. $\mathrm{KOH}$ in $\mathrm{EtOH}$ ). A chlorine-containing polymer is not ne- cessary for this reaction to occur.

The current work describes the initial investigations of films which combine (PVA), mixture of EV and BPB and chloral hydrate to give dosimeter films.

\section{Experimental}

\subsection{Preparation of Stock Dye Solutions of EV and BPB}

The stock of the dye was prepared by dissolving $0.08 \mathrm{~g}$ of ethyl violet dye (EV) (product of RIEDEL DEHAEN, Germany) in $50 \mathrm{ml}$ distilled water. Also, the stock solution of the sodium salt of the dye was prepared by dissolving $0.08 \mathrm{~g}$ of bromo-phenol blue (BPB) (product of CHAMPOL, Czech Republic) in $50 \mathrm{ml}$ distilled water. These two stock solutions were used in the preparation process of the mixed dye dosimetry film.

\subsection{Preparation of (EV-BPB)/PVA Mixed Dye Films}

10 grams of fully hydrolyzed poly vinyl alcohol (99\% $100 \%$ ) from J. T. Baker chemicals Co., USA were dissolved in $250 \mathrm{ml}$ doubly- distilled water at about $60^{\circ} \mathrm{C}$. The solution was kept well stirred at the same temperature of about $24 \mathrm{~h}$, then left to cool. To this solution $2 \mathrm{mg}$ of (EV-BPB) mixture was added and further stirred for 3 hour so as to obtain a uniformly colored PVA solution. To each $30 \mathrm{ml}$ of the well mixed solution $0.2,0.5,0.8$ and $1 \mathrm{~g}$ of chloral hydrate $\mathrm{CH}$ (from Merck Co.) were 
added. The dyed PVA solution are poured onto a $15 \times 15$ $\mathrm{cm}$ polyester sheet $(0.1 \mathrm{~mm}$ thickness $)$ fixed on a horizontal leveled glass plate and kept to dry in dark room at temperature $\left(25^{\circ} \mathrm{C} \pm 2^{\circ} \mathrm{C}\right)$. After stripping the films they were stored in dark at relative humidity of $35 \%$. The thicknesses of the films were measured using DigitrixMark II thickness gauge at 5 randomly selected places with a thickness gauge having an accuracy of $0.055 \pm$ $0.002 \mathrm{~mm}$.

\section{Instruments}

The absorption spectra of unirradiated and irradiated films were measured throughout the wavelength range 200 - $800 \mathrm{~nm}$ using a UVIKON 860 spectrophotometer. The film thickness was measured using a Digitrix-Mark II gauge (precision $\pm 1 \mu \mathrm{m}, 1 \sigma$ ). Irradiation was carried out with gamma radiation in the ${ }^{60} \mathrm{Co}$ gamma chamber 4000 A irradiation facility (product of India). The absorbed dose rate in the irradiation facility was measured to be $6.334 \mathrm{kGy} / \mathrm{h}$, using reference Alanine dosimeters. The electronic equilibrium conditions were maintained during irradiation.

\section{Results and Discussion}

\subsection{Absorption Spectra}

The absorption spectra of (EV-BPB)/PVA films without chloral hydrate recorded before and after irradiation to different doses are shown in Figure 1. The main absorption band in visible region characteristic to violet color peaking at $600 \mathrm{~nm}$. The amplitude of this band, decreases gradually with the increase of dose of $\gamma$-ray photon, at $\lambda_{\max } 600 \mathrm{~nm}$. The absorption spectra of unirradiated and irradiated films were measured throughout the wavelength range $200-800 \mathrm{~nm}$. The absorption spectra of these films with chloral hydrate recorded before and after irradiation to different doses are shown in Figure 2. The ampilitude of this band, decreases gradually with the increase of dose of $\gamma$-ray photon. It is clear from the spectra of irradiated film that, the mixed dyes (EV-BPB) degraded by applying of gamma rays on the film. Four different chloral hydrate concentrations 16.6, 41.6, 66.6 and $83.3 \mathrm{phr}$ with $0.3 \mathrm{phr}$ of (EV-BPB) were examined.

The acid sensitive dye in the film changes its color from violet to yellow by irradiation due to consequent lowering of the $\mathrm{pH}$ of the film caused by the $\mathrm{HCl}$ generated from the radiolysis of chloral hydrate [12].

\subsection{Response Curves}

For dosimetry, optical density read out was carried out at $600 \mathrm{~nm}$ for (EV-BPB)/PVA films for different concentration of chloral hydrate (16.6, 41.6, 66.6 and $83.3 \mathrm{phr})$. Figure 3 show the response curves in terms of change

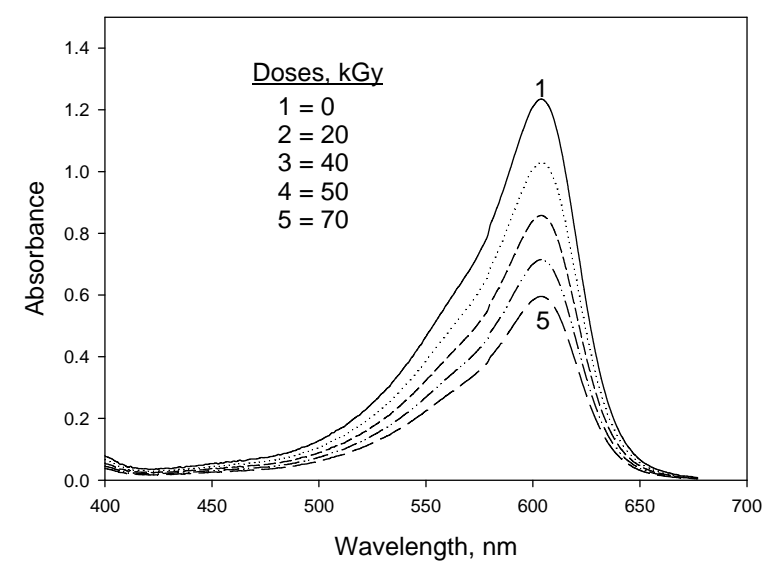

Figure 1. The absorption spectra of (EV-BPB)/PVA films unirradiated and irradiated to different absorbed doses.

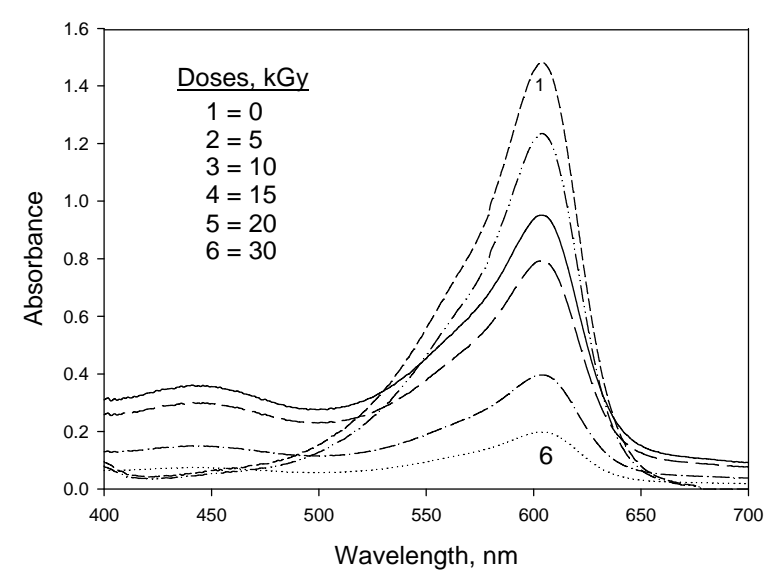

Figure 2. The absorption spectra of (EV-BPB)/PVA films containing chloral hydrate unirradiated and irradiated to different absorbed doses. [chloral hydrate] $=66.6 \mathrm{phr}$.

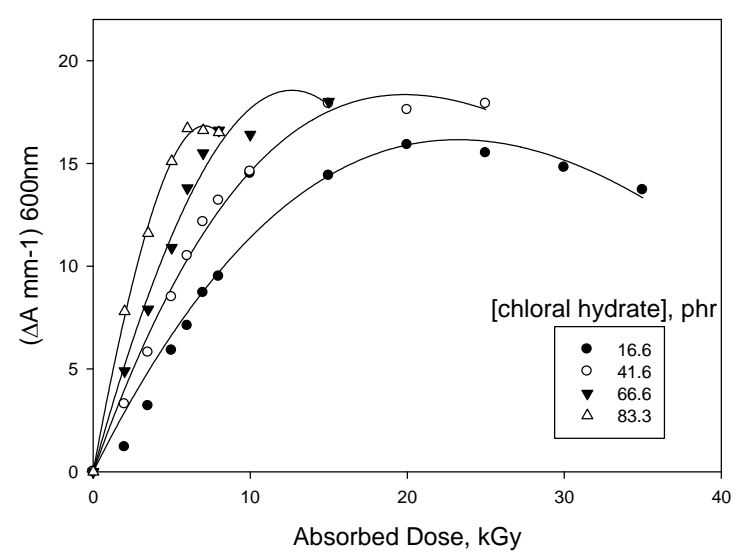

Figure 3. Change of $\Delta A \mathrm{~mm}^{-1}$ as a function of absorbed dose of EV-BPB/PVA films with different concentration of $\mathrm{CH}$ (measured at $600 \mathrm{~nm}$ ).

optical density per unit thickness $\Delta A=A_{o}-A_{i}$ where $A_{o}$ and $A_{i}$ are values of optical density for the unirradiated and irradiated films, respectively. The curves show that 
the useful dose range extends up to $30 \mathrm{kGy}$. It can be noticed that all curves show the same trend where they are linear up to about $15 \mathrm{kGy}$, then tend to saturate at higher doses. But, all curves differ in the response value (initial curve slope). Figure 4 shows the relation between the response value (initial curve slope) and the concentration of chloral hydrate. It can be seen that, the response increases by increasing the concentration of chloral hydrate.

Figure 5 shows the relation between the dose at saturation (reach saturation more than $95 \%$ of indicator changes its color) and the concentration of chloral hydrate. It can be seen that, the dose at saturation decreases with the increase of [CH] from 16.6 up to $83.3 \mathrm{phr}$. Plotting the concentration of chloral hydrate scale a straight line was obtained which can be expressed as follows:

$\mathrm{D}=21.8-0.23$ [chloral hydrate]

$\mathrm{D}$ is the dose at saturation in $\mathrm{kGy}$.

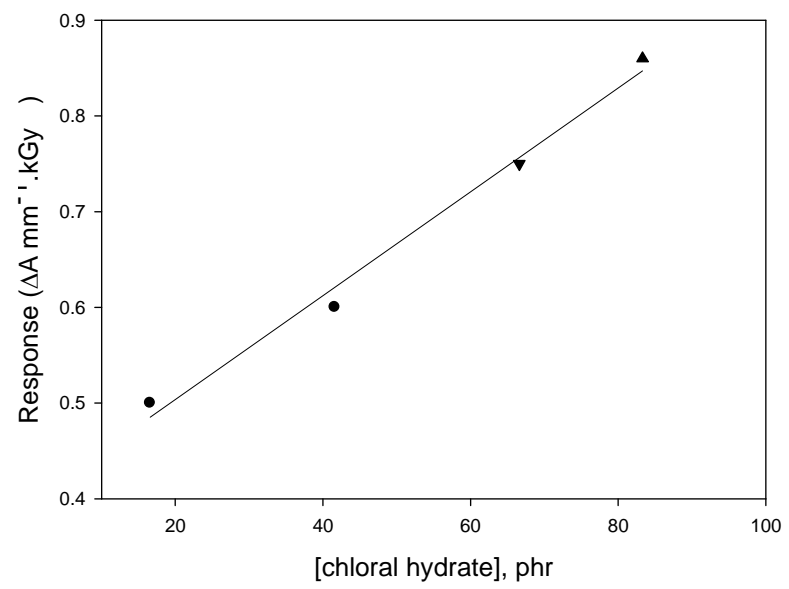

Figure 4. Change of response $\left(\Delta A \mathrm{~mm}^{-1} \cdot \mathrm{kGy}^{-1}\right)$ of $(\mathrm{EV}$ BPB/PVA) film as a function of concentration of chloral hydrate.

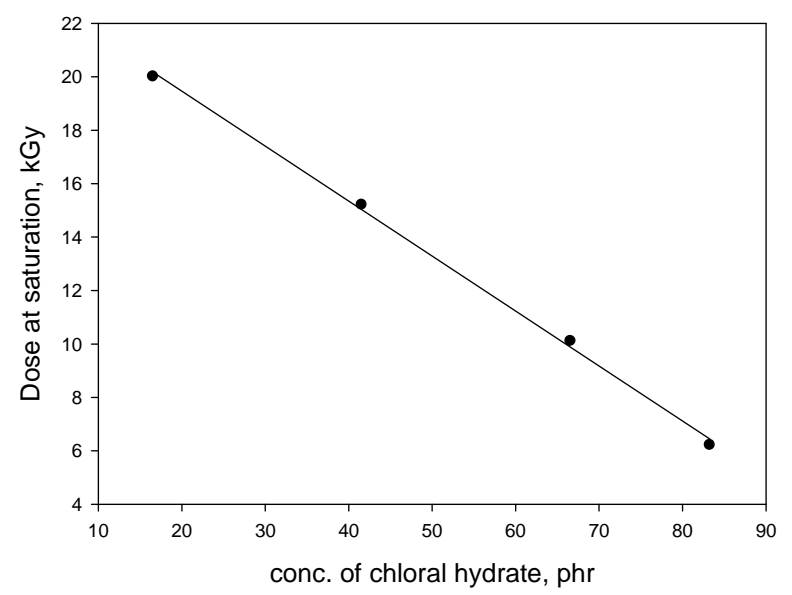

Figure 5. Variation of dose saturation, kGy, of EV-BPB/ PVA films as a function of concentration of both $\mathrm{CH}\left(\lambda_{\max }=\right.$ $600 \mathrm{~nm})$.

\subsection{Calculation of Concentration of Hydrogen Ion}

Figure 6 shows the total amount of $\mathrm{H}^{+}$ion in films containing different concentrations of chloral hydrate as a function of absorbed dose at $600 \mathrm{~nm}$ wavelength [13]. It can be seen that the amount of acid formed increases gradually with the increase of absorbed dose. The rate of increment of acid increases with the increase of both absorbed dose and concentration of chloral hydrate.

\subsection{Radiation-Chemical Yield}

The radiation-chemical yield (G-value) is defined here as the number of moles of dye degraded by the absorption of $1 \mathrm{~J}$ of energy (unit: $\mathrm{mol} / \mathrm{J}$ ). The G-value has been carried out by using the equation [14].

$$
G(- \text { dye })=\Delta A / D \cdot \varepsilon \cdot \rho \cdot b(\mathrm{~mol} / \mathrm{J})
$$

Using the dye concentration in $\mathrm{mol} / \mathrm{L}$ and the average value $\mathrm{L} \mathrm{mol}{ }^{-1} \cdot \mathrm{cm}^{-1}$ of $A_{o} / b$. The molar extinction coefficient is calculated as $1230.07 \mathrm{~L} \mathrm{~mol}^{-1} \cdot \mathrm{cm}^{-1}$ and the density of PVA $1.25 \mathrm{~g} \cdot \mathrm{cm}^{-3}$, the $G(-$ dye $)$ for the different chloral concentration $0.325 \mu \mathrm{mol} / \mathrm{J}, 0.481 \mu \mathrm{mol} / \mathrm{J}, 0.633$ $\mu \mathrm{mol} / \mathrm{J}$ and $0.76 \mu \mathrm{mol} / \mathrm{J}$. It can be seen that in Figure 7, the $\mathrm{G}$ (value) increase with the increase of chloral hydrate concentration.

\subsection{Assessment of Uncertainties}

To be meaningful, a measurement of gamma ray shall be accompanied by an estimate of the uncertainty in the measured value. Factors contributing to the total uncertainty may be separated into two types, type A and type B (ISO/ASTM, 2002 and N. B. Taylor et al., 1994). The first factor is associated mainly with the measuring equipment and the film and the second is mainly related to the calibration.

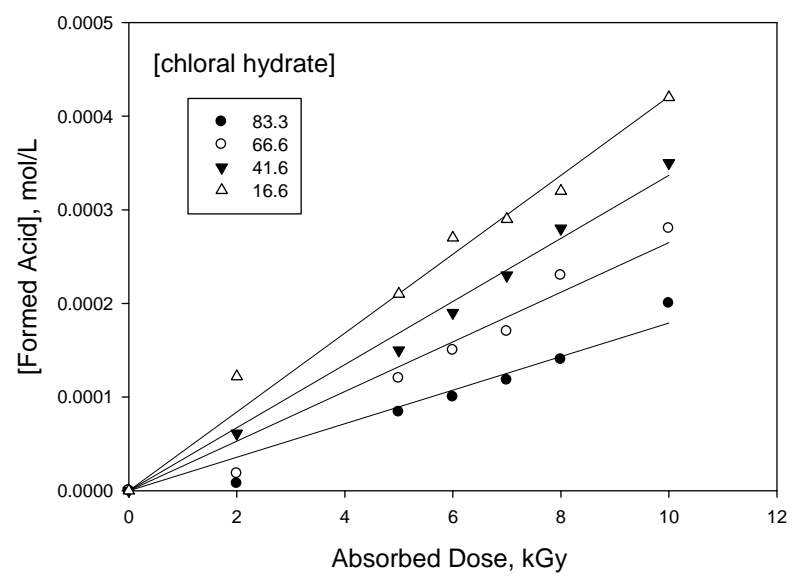

Figure 6. Concentration of radiation formed $\mathrm{HCl}$ in $\mathrm{EV}$ BPB/PVA films containing different chloral hydrate as a function of absorbed dose. $\lambda_{\max }=600 \mathrm{~nm}$. 


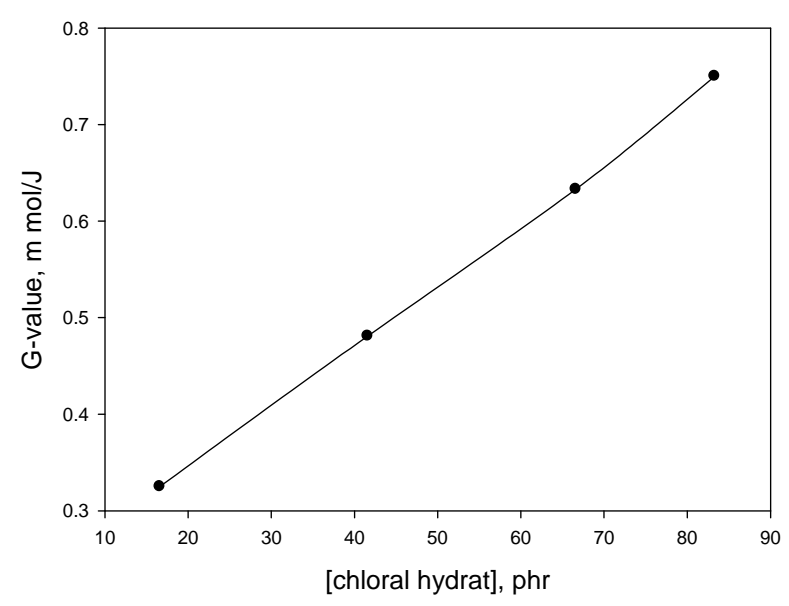

Figure 7. Change of G-value of (EV-BPB)/PVA as a function of chloral hydrate concentration.

The reproducibility of the Unicam UV-4 spectrophotometer was determined by reading the absorbance value (at $600 \mathrm{~nm}$ wavelength and absorbance level 0.8) of irradiated films several times. From the data obtained, it was found that the coefficient of variation (1 sigmalrm) is \pm $0.23 \%$, reflecting the precision of the spectrophotometer. The reproducibility of the Minitest thickness gauge was determined by reading the thickness value for (EVBPB)/PVA films several times. From the data obtained, it was found that the coefficient of variation (1 sigmalrm) is $\pm 0.7 \%$. The reproducibility of the measurements of several films (10 times for film) was found to be $0.9 \%$ $(1 \sigma)$.

On the other hand, the type A uncertainties (at one standared deviation, i.e. $1 \sigma$ ) arising during calibration over the useful response range were found to be $\pm 2.6 \%$. The combining all the components in quadrature at one standard deviation $1 \sigma$ as follows:

$$
U_{c}=\sqrt{(0.23)^{2}+(0.7)^{2}+(2.6)^{2}+(0.9)^{2}}=2.8 \% .
$$

The combined uncertainty (at two standard deviations, i.e. $2 \sigma$, approximately equal to a $93 \%$ confidence level) is found by multiplication of $U_{c}$ (at $1 \sigma$ ) by two. Hence the combined uncertainty using (EV-BPB)/PVA film is $5.6 \%$.

\section{Stability}

\section{Post-Irradiation Stability}

The post irradiation stability for EV-BPB/PVA films containing $66.6 \mathrm{phr}$ of $\mathrm{CH}$ and irradiated to $20 \mathrm{kGy}$ is investigated by storing them in dark at $25^{\circ} \mathrm{C}$ and under laboratory fluorescent lights at the same temperature.

The absorbance of these films was measured at 600 $\mathrm{nm}$ at different intervals of the time during the post-irradiation storage period of 60 days, as shown in Figure 8.

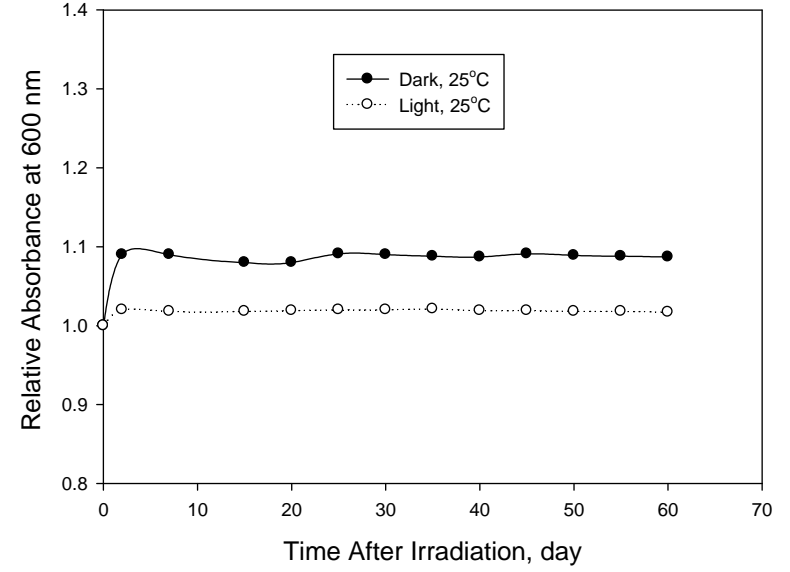

Figure 8. Post-irradiation stability of (EV-BPB)/PVA film stored under different storage conditions.

The films show excellent stability under all storage conditions.

\section{Conclusion}

Films made of PVA dyed with ethyl violet and bromophenol blue are useful radiation dosimeters in the dose range up to $70 \mathrm{kGy}$ while these films containing chloral hydrate $(16.6-83.3 \mathrm{phr})$ are useful in the range $5-30$ $\mathrm{kGy}$. The films are highly stable for long times after irradiation under different storage conditions. These properties suggest them to be useful for routine monitoring and dose mapping in radiation processing. They are easy to prepare in a laboratory and do not require toxic solvents in the preparation.

\section{REFERENCES}

[1] K. M. Glover, M. King and M. F. Watts, "Calibration and Intercomparison of Red 4034 Perspex Dosimeters," Proceedings of the International Symposium International Symposium on High-Dose Dosimetry, Vienna, 8-12 October 1985, International Atomic Energy Agency, p. 373.

[2] B. Whittaker, "Radiation-Sensitive Material," UK Patent Application GB 2182941A, 1988.

[3] D. F. Regulla and U. Deffiner, "Dosimetery by ESR Spectroscopy of Alanine," The International Journal of Applied Radiation and Isotopes, Vol. 33, No. 11, 1982, pp. 1101-1114. doi:10.1016/0020-708X(82)90238-1

[4] F. Abdel-Rehim and A. A. Abdel-Fattah, "A Thin-Film Radiation Monitoring Label and Dosimetery System," Applied Radiation and Isotopes, Vol. 44, No. 7, 1993, pp. 1047-1053. doi:10.1016/0969-8043(93)90010-8

[5] S. Matsumoto, T. Tsukada, K. Umetsu and H. Fukaya, "Plastic Radiation Indicator of the Color Change Type," US Patent, Vol. 3, 1973, pp. 743-846.

[6] Y. Hori, N. Yoshikawa and S. Ohmori, "Plastic for Indicating a Radiation Dose," US Patent No. 3899677, 1975.

[7] B. Whittaker, "The GAMMACHROME YR System," 
NPL Report RS (RXT) 97, Dosimetery and Control Processing, Symposium of UK Panel on Gamma Ellectron Irradiation, National Physical Laboratory, Teddington, 1988, p. 18.

[8] S. S. Yasser, "Development of Some Polymeric Materials for Possible Use as Radiation Dosimetery System," M.Sc. Thesis, Chemistry Department, Faculty of Science, BeniSuef Branch, Cairo University, Cairo, 2005, p. 53.

[9] S. Ebraheem and W. B. Beshir, "Investigation of Dyed Film Based on 2,6-Dichlorophenol-iodophenol Dyed Poly (Vinyl Alcohol) and Poly (Vinyl Butyral) for Possible Use in High-Dose Processing Dosimetery," Arab Journal of Nuclear Sciences and Applications, Vol. 38, No. 1, 2005, pp. 15-22.

[10] A. Kovacs and S. Ebraheem, "A New Dyed Poly (Vinyl Alcohol) Film for High-Dose Application," Radiation Physics and Chemistry, Vol. 63, No. 3-6, 2002, pp. 807811. doi:10.1016/S0969-806X(01)00663-6
[11] K. Ueno, "Development of a Plastic Dosimeter for Industrial Use with High Doses," Radiation Physics and Chemmistry, Vol. 31, No. 4-6, 1988, pp. 467-472.

[12] A. A. Abdel-Fattah, M. El-Kelany and F. Abdel-Rehim, "Development of a Radiation-Sensitive Indicator," Radiation Physics and Chemistry, Vol. 48, No. 4, 1996. pp. 497-503. doi:10.1016/0969-806X(96)00014-X

[13] A. A. Abdel-Fattah and M. El-Kelany, "Radiation Sensitive Indicators Based on Bromophenol Blue and Chloral Hydrate Dyed Polyvinyl Butyral," Radiation Physics and Chemistry, Vol. 51, No. 3, 1998, pp. 317-325. doi:10.1016/S0969-806X(97)00258-2

[14] W. L. McLaughlin, A. W. Boyd, K. H. Chadwich, J. C. McDonald and A. Miller, "Dosimetry Radiation Processing,” Taylor \& Francis, London, 1990. 